\title{
Electrochemical technology for environmental treatment and clean energy conversion*
}

\author{
F. C. Walsh \\ Electrochemical Engineering Group, Department of Chemical Engineering, \\ University of Bath, Claverton Down, Bath BA2 7AY, UK
}

Abstract: The applications of electrochemical technology in environmental treatment, materials recycling, and clean synthesis are briefly reviewed. The diversity of these applications is shown by the number of industrial sectors involved. The scale of operation ranges from microelectrodes to large industrial cell rooms. The features of electrochemical processes are summarized.

Available and developing electrode designs are considered and illustrated by examples including the regeneration of chromic acid electroplating baths, metal ion removal by porous, 3-dimensional cathodes, rotating cylinder electrodes (RCEs), and a reticulated vitreous carbon (RVC) RCE. The use of performance indicators based on mass transport, electrode area, and power consumption is emphasized.

Electrochemical reactors for energy conversion are considered, with an emphasis on load-leveling and proton-exchange membrane (PEM) (hydrogen-oxygen) fuel cells. Ionexchange membranes play an essential role in such reactors, and the variation of electrical resistance vs. membrane thickness is described for a series of extruded, Nafion ${ }^{\circledR} 1100 \mathrm{EW}$ materials. The characterization of high-surface-area, platinized Nafion surfaces is also considered. The development of modular, filter-press cells as redox flow cells in electrical loadleveling applications is concisely described.

Trends in electrode, membrane, and reactor design are highlighted, and the challenges for the development of improved reactors for environmental treatment are noted.

\section{INTRODUCTION}

There are increasing economic, social, legal, and environmental pressures to utilize the "best available technology" not entailing excessive cost and to aspire to "performance without pollution", i.e., "zero pollution processing". Electrochemical technology has an important role to play as part of an integrated approach to the avoidance of pollution, monitoring of pollution and process efficiency, cleaner processing, and modern techniques for electrical energy storage and conversion.

Electrochemical technology [1-5] continues to make many contributions to environmental treatment, recycling, and monitoring [6-11]. As shown by the examples in Table 1, electrochemistry can play many roles in clean technology and pollution control:

a) the avoidance of polluting reagents in materials synthesis, such as zinc powder for organic reductions, by the use of direct electron transfer

b) the monitoring of pollutant and reagent levels in process streams, rinse sections, effluents, and gaseous emissions

\footnotetext{
*An issue of reviews and research papers based on presentations made at the IUPAC/ICSU Workshop on Electrochemistry and Interfacial Chemistry in Environmental Clean-up and Green Chemical Processes, Coimbra, Portugal, 6-7 April, 2001.
} 
c) the treatment of water by electrochemically generated species, such as chlorination of swimming pools and sterilization of medical instruments using a powerful cocktail of oxidizing reagents in "superoxidized" water

d) the removal of environmental contaminants, such as metal ions and organics from industrial process streams

e) the clean conversion of chemical to electrochemical energy using fuel cell and photovoltaic devices

Continued developments in our understanding and documentation of the electrodes and membranes $[12,13]$ and electrochemical reactor design $[14,15]$ together with increasing industrial experience of their use [16,17] are resulting in a more widespread acceptability of electrochemical technology and its features (Table 2).

Table 1 The scope for electrochemical technology in environmental treatment.

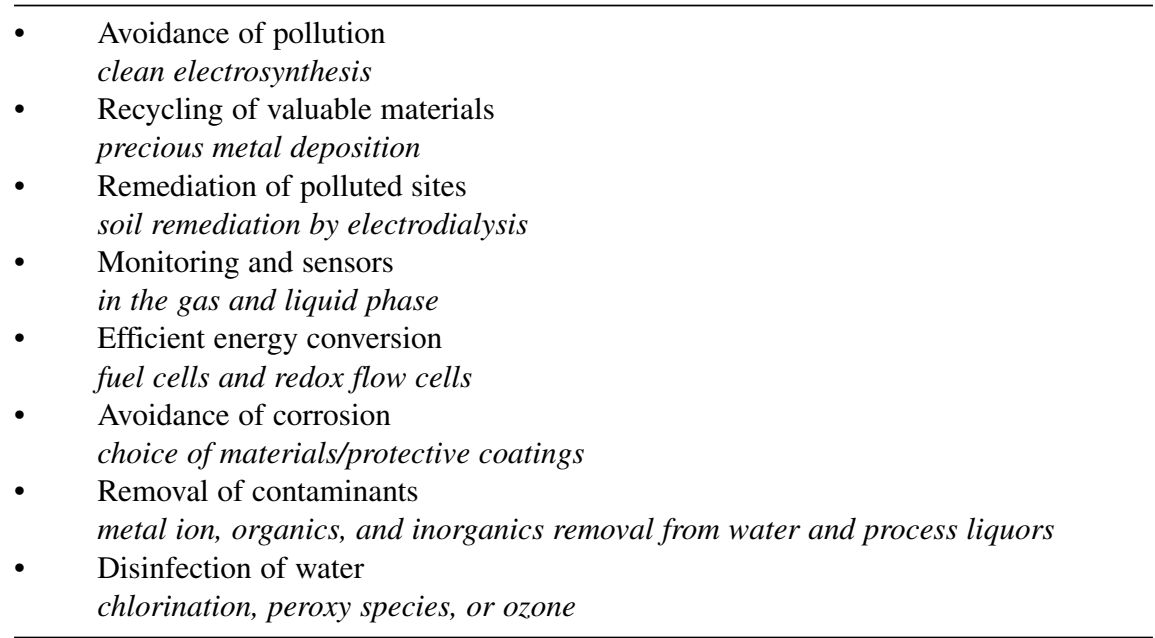

Table 2 The advantages and limitations of electrochemical technology.

\section{The Many Advantages}

- $\quad$ Electrons are clean reagents (at least at their source of supply).

- $\quad$ Effective control of the electron transfer rate (current density).

- Measurement of reaction conditions (current density and electrode potential).

- $\quad$ The process can be turned on and off via the current.

- $\quad$ Can often use benign (e.g., ambient) conditions of temperature and pressure.

\section{Possible Limitations}

- Many research workers have little industrial/large-scale experience of electrochemical technology, hindering technology transfer.

- $\quad$ Some industrial sectors have limited knowledge or experience of electrochemical technology.

- There are relatively few "showcases" for the technology.

- There is a shortage of experienced electrochemical engineers.

- Chemical reactions, corrosion, adsorption, etc., at electrode surfaces can cause complications.

- Damage to electrodes and membranes via, e.g., corrosion and fouling, can restrict performance and longevity. 
The scale of electrochemical technology is diverse and ranges from single microelectrode probes of perhaps $10^{-10} \mathrm{~m}^{2}$ through to large parallel plate cell houses of total electrode area $<10^{4} \mathrm{~m}^{2}$ in chloralkali industry and load-leveling redox flow cell developments [5]. The total cell current can vary from $10^{-9} \mathrm{~A}$ up to $>10^{6} \mathrm{~A}$ (Fig. 1). This range continues to expand, particularly at the lower end of the scale of current and surface area, due to development in microelectrode probes for chemical analysis and scanning probe microscopies for advanced imaging of surfaces. The present paper considers examples of electrochemical reactors that have been used in applications in the general range 0.0001 to $1000 \mathrm{~m}^{2}$ (involving currents of $<10^{-2}$ A to $>100 \mathrm{kA}$. The emphasis is on the removal of contaminants from (and the regeneration of) aqueous solutions, together with improvements in electrode and membranes used for energy conversion and storage applications. In the case of analytical applications of environmental electrochemistry, the reader is directed to a review [17] and to other contributions in this special issue.

Laboratory and pilot scale studies

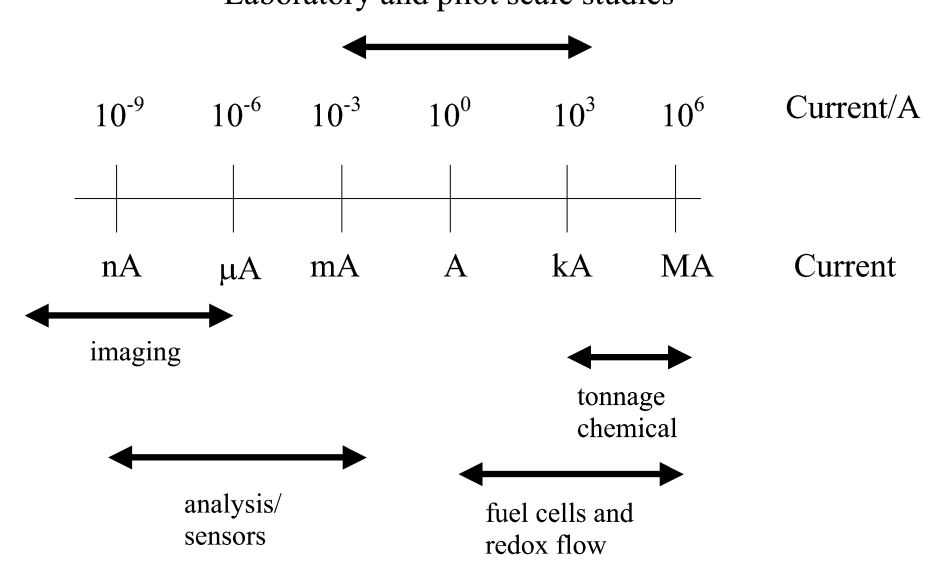

Fig. 1 The scale of electrochemical technology: beyond nanoamperes to megaamperes.

\section{ELECTRODE AND REACTOR DESIGN}

\section{Factors affecting the selection of an electrochemical reactor}

It is important to design (or select) an electrochemical reactor for a specific process, and it is clear that reactors for energy conversion and electrochemical synthesis will have different drivers to those used in the destruction of electrolyte-based contaminants. Figure 2 shows some of the decision processes involved in the selection of electrochemical reactor design. Adequate attention must be paid to the form of the electrode, its geometry and motion, together with the need for cell division or a thin electrolyte gap [18]. The form of the reactants and products and the mode of operation (batch or continuous) are also important design factors $[1,2]$.

Desirable factors in reactor design (and their implications) include [18]:

a) moderate costs (low-cost components, a low cell voltage, and a small pressure drop over the reactor)

b) convenience and reliability in operation (designed for facile installation, maintenance, and monitoring)

c) appropriate reaction engineering (uniform and appropriate values of current density, electrode potential, mass transport, and flow)

d) simplicity and versatility (in an elegant design, which is attractive to end users) 


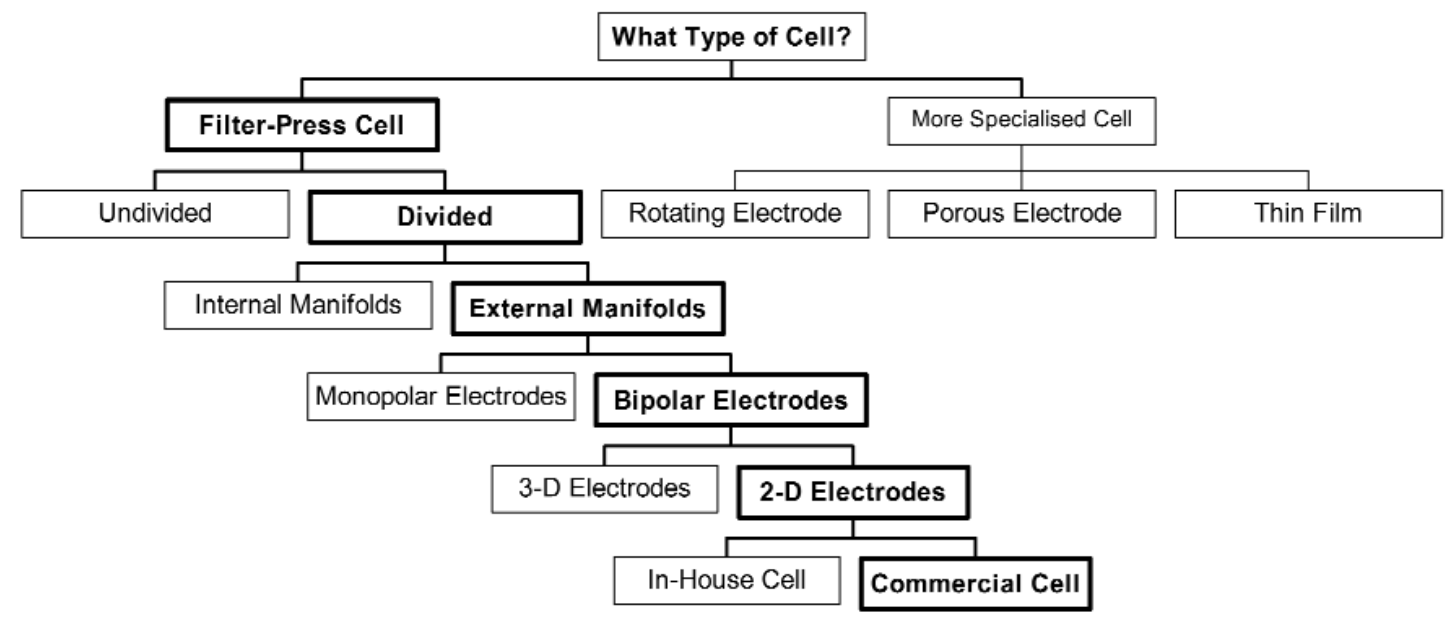

Fig. 2 Decisions during the process of selecting an electrochemical reactor. The route shown in boldface indicates the selection of an undivided, 2-dimensional bipolar filter-press cell. (More specialized reactors are required for many applications such as metal ion removal from dilute solution).

Problem areas for electrode technology and stability may be listed as:

a) activity and surface area changes due to catalysis, blockage, and potential-distribution

b) adsorption/desorption of reactant, product, intermediates, contaminants

c) film formation/removal via, e.g., passivation or polymerization

d) phase transformation, e.g., solid-solid, intercalation, dehydration

Ion-exchange membranes [13] can play a critical role in electrochemical reactors; their advantages and drawbacks are summarized in Table 3, while Table 4 provides a list of the essential features of electrodes and membranes in electrochemical reactors. The many reactor designs described in the scientific and engineering literature can be distilled down to a very few examples of industrially important reactors on the pilot and full commercial scale.

Table 3 The essential features required from electrodes and ion-exchange membranes in electrochemical reactors

- $\quad$ high surface area electrodes $\left(A_{e}\right)$

- $\quad$ high mass transport to electrodes $\left(\right.$ high $\left.k_{m}\right)$

- $\quad$ good electrocatalysis at the electrode surface ( $h i g h j_{o}$ desired reaction)

- $\quad$ acceptable cost, lifetime, and practicality of electrodes and membranes

- $\quad$ high conductivity and ease of connection to electrodes

- low potential drop over electrodes and membranes

- membranes that are selective to a particular ion

- low solvent transport rate through membranes 
Table 4 The advantages and drawbacks of ion-exchange membranes in electrochemical reactors.

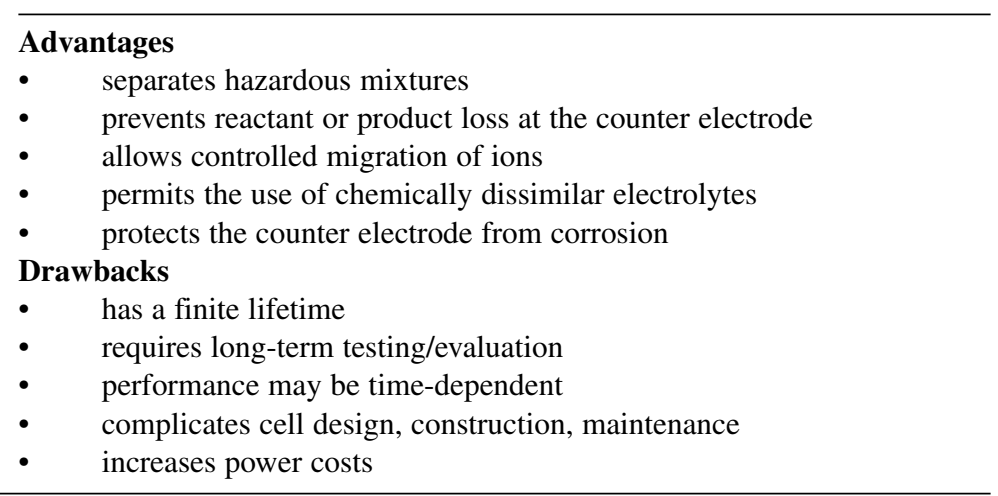

\section{Important factors in reactor performance}

There are many compromises during the process of reactor design/selection in order to accommodate the large number of factors acting as drivers:

a) uniform current density distribution

b) uniform electrode potential distribution

c) high mass transport rates

d) ability to handle solid, liquid, or gaseous products.

e) the form of the product and the ease of product extraction

f) simplicity of design, installation, and maintenance

g) availability of electrode and membrane materials

h) capital and running costs

i) integration with other process needs

The energy efficiency of a reactor depends on the cell voltage, which can be expressed as a number of voltage components:

$$
E_{\text {cell }}=E_{\text {cell }}^{e}-\sum|\eta|-\sum I R
$$

where the terms on the right-hand side represent the thermodynamic equilibrium cell voltage, the sum of the overpotentials at each electrode, and the sum of all ohmic drops in the reactor due to current $(I)$ flow through resistances $(R)$. It is important to minimize overpotential and ohmic components of voltage in order to maximize energy efficiency. Appropriate strategies include the use of conductive, catalytic electrodes and membranes, the use of small inter-electrode (or membrane-electrode) gaps, and careful choice of the counter electrode chemistry to minimize the equilibrium cell voltage term.

It is common to have a low reactant concentration $(c)$ in environmental treatment and to require compact treatment units in a restricted space. Under such conditions, the rate of contaminant removal in a $\mathrm{Z}$ electron change process is often mass transport limited, and a high-performance reactor needs to have a high mass transport coefficient $\left(k_{m}\right)$ and enhanced electrode area $(A)$ in order to achieve a high limiting current $\left(I_{L}\right)$ :

$$
I_{L}=k_{m} A z F c
$$

High mass transport rates can be achieved by the use of electrode movement, including reciprocation of planar electrodes and moving bed electrodes or rotating cylinder reactors while high surface area per unit volume can be achieved by the use of porous, 3-dimensional electrodes [19]. 
The calculation of figures of merit [1-4,18] enables a close and quantitative comparison of electrochemical reactors (or a comparison among rival treatment technologies). Important performance indicators for environmental treatment reactors include the normalized space velocity $\left(s_{n}\right)$ [4]. This parameter represents the volume of effluent that can be treated in a unit volume reactor in unit time, such that a 10 -fold reduction in reactant level takes place. For a plug flow reactor (volume, $V_{R}$ ) operating under complete mass transport controlled conditions:

$$
s_{n}=\frac{k_{m} A}{2.3 V_{R}}
$$

In addition, the importance of the product of mass transport coefficient and electrode area is once again clear.

The cost of electrolysis is directly related to the electrolytic power consumption [20]. A normalized value may be calculated to represent the power consumed in treating a unit volume of electrolyte per unit electrode volume in unit time, such that $90 \%$ of the reactant is removed [21]:

$$
W_{n}{ }^{V}=\frac{k_{m} A_{e} E_{\mathrm{cell}} q}{2.303 V_{R}}
$$

where $k_{m}$ is the mass transport coefficient, $A_{e}$ is the electrode area per unit electrode volume, $E_{\text {cell }}$ is the cell voltage, $q$ is the electrical charge and $V_{R}$ is the reactor volume.

\section{METAL ION REMOVAL FROM PROCESS SOLUTIONS}

\section{Regeneration of chromic acid electroplating baths}

In the case of metal ion removal, some of the challenges to electrochemistry (and indeed, other techniques of pollution control) are provided by the diversity of industrial sector together with the form of the contaminant (e.g., solid, liquid, or gas, sludges, colloids) and the complexity of the electrolyte (many ionic and uncharged species can be present). The general sources of metal ion process streams are summarized in Table 5 [22].

Table 5 The sources of metal ion-containing process streams.

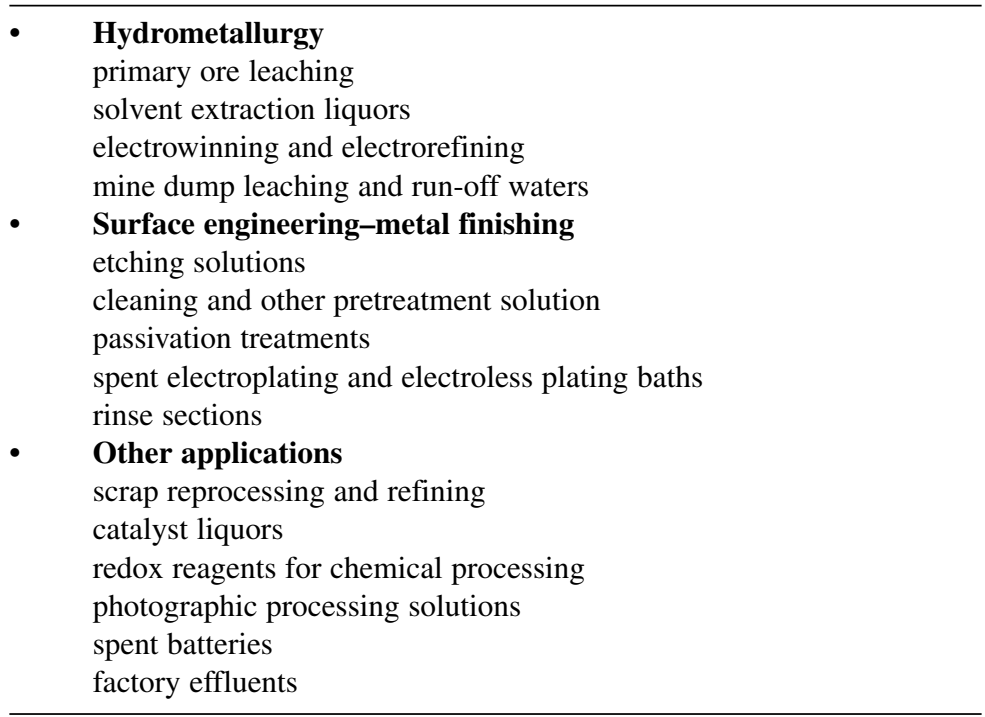


Electrochemical techniques offer several approaches to the removal of metal ions from solution. Controlled migration of ions through ion-exchange membranes can be used to remove some cations, while it is also possible to precipitate the metal as the hydroxide due to an increasing near cathode $\mathrm{pH}$. In other processes, anodically generated iron(III) or aluminium(III) ions can be used to precipitate or flocculate metal hydroxides $[1,9]$. In other cases, it is possible to regenerate a process solution by reduction or oxidation of the active species.

For example, chromic acid plating baths can become contaminated with substrate metals (such as iron, copper, and zinc), and the $\mathrm{Cr}(\mathrm{VI})$ content decreases as $\mathrm{Cr}(\mathrm{III})$ builds up. These contaminants result in deterioration of the chromium deposit, which can suffer from roughness, pitting, and reduced wear resistance, while the cathode efficiency for chromium deposition can drastically decrease. The chromic acid bath may be treated by a combination of controlled, cascade water rinse/air extraction system and electrodialysis (Fig. 3) [23] to produce minimum effluent and an electroplating solution, which has depleted iron, copper. and zinc (removed at the cathode of the electrodialysis cell) and regenerated $\mathrm{Cr}(\mathrm{VI})$ (at the anode). Following laboratory trials on a $64 \mathrm{~cm}^{2}$ filter-press cell, an electrodialysis unit was constructed and operated at Poeton Industries (Gloucester, UK). The electrodialysis stack was divided by fluorocarbon-based cation-exchange membranes (Nafion 450) and contained 12 lead anodes and cathodes, each $0.12 \mathrm{~m}^{2}$ in area. The typical current density was $200-500 \mathrm{~A} \mathrm{~m}^{-2}$. The electrodialysis stack was installed into a recycle loop on the chromic acid $\left(55{ }^{\circ} \mathrm{C}, 1400 \mathrm{dm}^{3}\right)$ process tank and allowed a reduction in effluent waste of around 500 litres per day, a $70 \%$ reduction in water consumption and an $80 \%$ reduction in chromium loss. The trivalent chromium levels in the plating bath were maintained at levels down to $2-6 \mathrm{~g} \mathrm{dm}^{-3}$ while the iron contamination was kept below $3 \mathrm{~g} \mathrm{dm}^{-3}$. Over a four-month period, the electrodialysis unit was estimated to have removed $112 \mathrm{~kg}$ of trivalent chromium and $20 \mathrm{~kg}$ of dissolved iron [23].

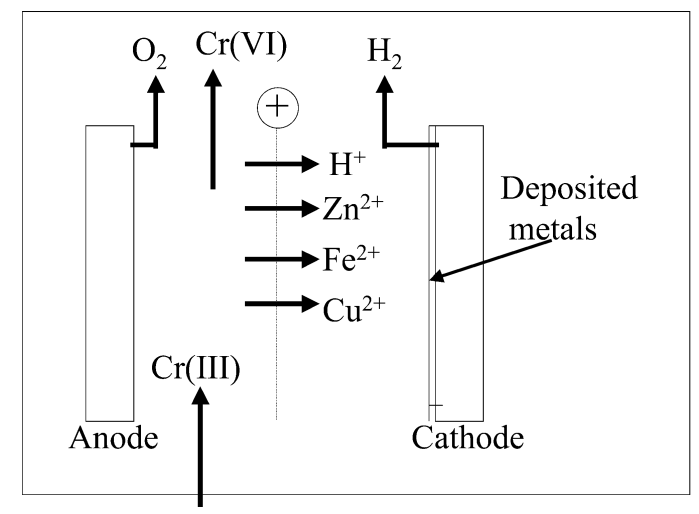

Fig. 3 Regeneration of chromic acid electroplating baths, showing the principle of electrodialytic removal of dissolved copper, zinc, and iron together with reoxidation of $\mathrm{Cr}(\mathrm{III})$ to $\mathrm{Cr}(\mathrm{VI})$.

\section{Removal of metal ion by cathodic deposition}

It is common for process liquors and rinse waters to contain relatively low concentrations of dissolved metal (typically $<<1000 \mathrm{ppm}$ ). Such low levels require high mass transport to the cathode surface and/or high surface area electrodes to provide a high production rate of metal with reasonable current efficiency. In the case of poorly conductive electrolytes, a thin film cell is useful. Three examples of a reactor design and process strategy may be given: 
a) Metal can be deposited on a high surface area per unit volume cathode having a porous, 3-dimensional structure. Following deposition onto porous carbon materials (typically felt, mesh, fiber, or foam) the metal may be recovered by furnace refining or by dissolution into a small volume of a corrosive electrolyte. An example is the deposition of copper onto reticulated vitreous carbon in a divided flow-by cell having a rectangular cross-section [24].

b) Metal can be deposited as flake or powder onto the surface of an inner rotating cathode cylinder (usually stainless steel). This allows metal to be scraped off the cathode drum and continuously fluidized out of the reactor followed by conventional methods of solid/liquid separation (e.g., hydrocycloning, filtration, and gravity settlement) [25]. In the majority of RCE reactors, the metal is removed discontinuously from the cathode by peeling and stretching of the cathode surface as in the case of silver extraction from fixer solutions [26] where many hundreds of units are in use throughout the photographic and metal refining industries.

c) Metal may be deposited onto the cathode surfaces of a thin electrolyte film reactor, such as a bipolar trickle tower reactor [22,27]. Such reactors are readily constructed from alternating layers of porous carbon (typically 3-12 mm thick and thin insulating meshes, ca. $1 \mathrm{~mm}$ thick). The anode sites of this undivided cell allow other solution species, e.g., EDTA or cyanide complexants to be oxidized. As in the case of the porous, 3-dimensional cathode reactor, metal may be removed from the tower by dissolution into a concentrate or by removal of the packing followed by furnace refining.

The removal of metal ions by electrodeposition onto a porous, 3-dimensional cathode can be illustrated by data from reticulated vitreous carbon (RVC) operated in a batch recycle mode. In laboratory studies, we have used a $50 \times 50 \times 12 \mathrm{~mm} \mathrm{RVC}$, flow-by, cathode of $100 \mathrm{ppi}$ (pores per inch) in a Nafion 324 divided cell with oxygen evolution at an inert counter electrode [21,24]. As an example of the challenges in treating a mixed metal solution, $10 \mathrm{ppm}$ of $\mathrm{Cu}(\mathrm{II}), \mathrm{Cd}(\mathrm{II})$, and $\mathrm{Zn}(\mathrm{II})$ ions has been studied in nitrogen-purged $0.1 \mathrm{M} \mathrm{NaCl}$ at $\mathrm{pH} 7$ and $295 \mathrm{~K}$ [28]. The decay of metal ion concentration in the $3 \mathrm{dm}^{3}$ reservoir, at a mean linear velocity of $0.083 \mathrm{~m} \mathrm{~s}^{-1}$ past the cathode surface, is shown in Fig. 4. Over the first $60 \mathrm{~min}$, a potential of $-0.5 \mathrm{~V}$ vs. SCE was applied to the cathode to selectively remove copper ions (although some cadmium ions are removed). For the next $60 \mathrm{~min}$, the potential was maintained at -1.0 $\mathrm{V}$ vs. SCE. Cadmium ion removal was achieved with some zinc ion removal. Finally, the last 60 mins

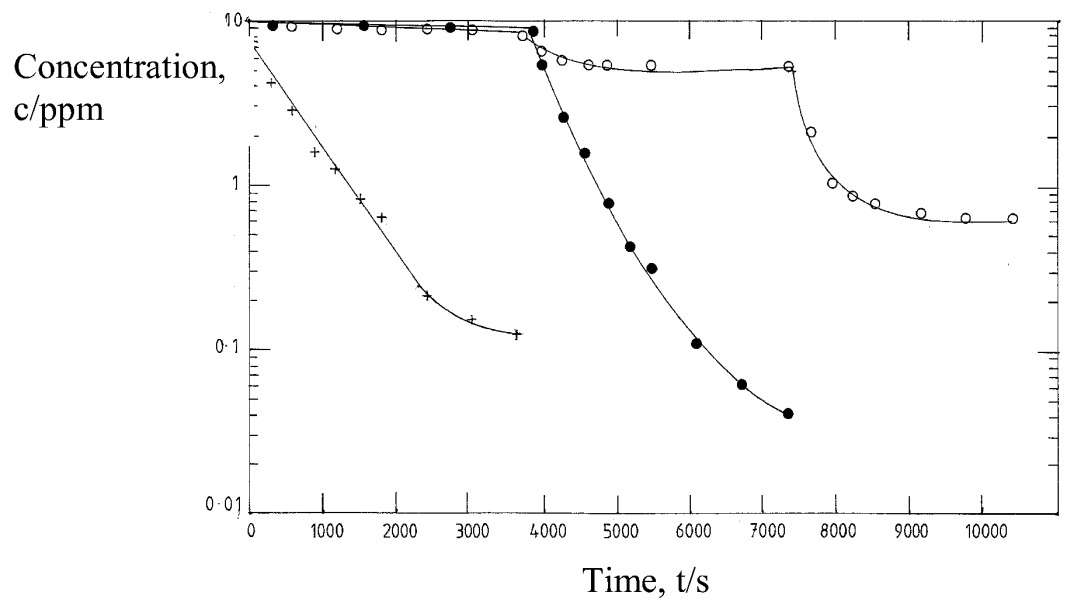

Fig. 4 Concentration decay of $\mathrm{Cu}(\mathrm{II}), \mathrm{Cd}(\mathrm{II})$ and $\mathrm{Zn}(\mathrm{II})$ ions with time during batch recirculation of $3 \mathrm{dm}^{3}$ of a $0.1 \mathrm{M} \mathrm{NaCl}$ solution at $298 \mathrm{~K}$ through a 100 ppi reticulated vitreous carbon cathode. The cathode potential was $-0.5 \mathrm{~V},-1.0 \mathrm{~V}$, and $-1.4 \mathrm{~V}$ vs. SCE for times of 0-60 min, 60-120 min, and 120-180 min, respectively. 
of the experiment involved a potential of $1.4 \mathrm{~V}$ vs. SCE to remove the remaining zinc ions. The final metal ion levels were $<0.1 \mathrm{ppm} \mathrm{Cu}(\mathrm{II}),<0.05 \mathrm{ppm} \mathrm{Cd}$ (II), and $<0.5 \mathrm{ppm} \mathrm{Zn}$ (II). Under the experimental conditions, the removal of metal ions takes place through both direct electrodeposition and the deposition of metal hydroxides via a near cathode increase in $\mathrm{pH}$. When treating pure $\mathrm{Cu}$ (II) solutions at the $1 \mathrm{mM}$ level, the above reactor was used to evaluate a range of cathode materials. Table 6 shows a comparison of the normalized space velocity and volumetric power consumption (electrolysis) for the treatment of $1 \mathrm{mM} \mathrm{Cu}^{2+}$ ions at $295 \mathrm{~K}$. The superiority of higher grades of RVC and, particularly, of carbon felt materials is clear (although RVC allows a much lower pressure drop through the cell).

Rotating cylinder electrodes (RCEs) have been used for many years in specialized reactors for metal removal. The RCE is usually surrounded by carbon anodes and rotates at speeds of 50-300 rpm. Specialized, divided, and scraped RCE reactors can be used for the continuous removal of metal as powder [29-32]. A more common reactor configuration is used in the removal of silver from photographic processing liquors, particularly thiosulphate-based fixer solutions [32]. Thousands of these reactors are used in the photographic processing and metals recyling industries. The RCE size typically ranges from 10-30 cm diameter RCEs at speeds of 50-500 rpm and currents of 10-500 A. The majority of these devices perform extremely well and permit fixer recycling as well as providing silver for resale. The use of rotating electrodes does, however, require attention to design and maintenance. Figure 5 provides a summary of fault conditions experienced over some 20 years of troubleshooting. These fault conditions are readily avoided or remediated by adequate attention to reactor design and maintenance procedures.

It is possible to combine the advantages of controlled flow of the RCE with the high surface area of porous, 3-dimensional carbon in RVC RCEs, i.e., rotating cylinder electrodes made from reticulated vitreous carbon. Such laboratory electrodes [33] are useful in obtaining data on metal concentration decay over a wide concentration range. As an example, we can consider an RCE of 100 ppi RVC (diameter $=1.0 \mathrm{~cm}$ and length $=1.2 \mathrm{~cm}$ ) rotated at $1500 \mathrm{rpm}$ in an electrolyte initially containing $0.50 \mathrm{mmol}$ $\mathrm{dm}^{-3} \mathrm{Cu}$ (II) ions and $0.50 \mathrm{mmol} \mathrm{dm}^{-3} \mathrm{Cd}(\mathrm{II})$ ions in deoxygenated $0.50 \mathrm{~mol} \mathrm{dm}^{-3} \mathrm{Na}_{2} \mathrm{SO}_{4}$ at $\mathrm{pH} 2$ and $298 \mathrm{~K}$. The decay of both metal ions (Fig. 6a) was mass transport controlled. During this time, the level of cadmium ions remained at its initial value. When the potential was changed to $-1000 \mathrm{mV}$ vs. SCE, the decay of cadmium ions occured according to a steady, mass-transport-controlled rate. When the concentration of dissolved cadmium had reached approximately $0.05 \mathrm{mmol} \mathrm{dm}{ }^{-3}$, the rate of decay slowed. No change in the copper level was observed during this period. The values of $k_{m} A_{e}$ for the concentration decay curves for both metals were approximately $0.3 \mathrm{~s}^{-1}$. The current efficiencies for the copper and cadmium deposition reactions are shown in Fig. $6 \mathrm{~b}$ as current efficiency vs. the normalized experimental time plots. The removal of copper showed a current efficiency of approximately $80 \%$

Table 6 Figures of merit for the performance of 3-dimensional carbon cathodes in a flow-by reactor (catholyte channel $50 \times 50 \times 12 \mathrm{~mm}$ ) during $\mathrm{Cu}^{2+}$ removal from $1 \mathrm{mM} \mathrm{CuSO}_{4}\left(63\right.$ to $6.3 \mathrm{ppm}$ ) in $0.5 \mathrm{M} \mathrm{Na}_{2} \mathrm{SO}_{4}$ at $298 \mathrm{~K}$. Based on a mean flow velocity of approximately $0.08 \mathrm{~m} \mathrm{~s}^{-1}$.

\begin{tabular}{lcc}
\hline $\begin{array}{l}\text { Type of 3-D } \\
\text { carbon electrode }\end{array}$ & $\begin{array}{c}\text { Normalized } \\
\text { space velocity, } s_{n} \\
/ \mathrm{m}^{3} \mathrm{~m}^{-3} \mathrm{~h}^{-1}\end{array}$ & $\begin{array}{c}\text { Normalized } \\
\text { volumetric power } \\
\text { consumption, } W_{n} \\
/ \mathrm{kW} \mathrm{m}^{-3}\end{array}$ \\
\hline 30 ppi RVC & 85 & 1.9 \\
60 ppi RVC & 136 & 2.8 \\
100 ppi RVC & 350 & 6.4 \\
Carbon cloth & 490 & 7.0 \\
Carbon granules & 200 & 5.8 \\
Carbon felt & 590 & 6.8 \\
\hline
\end{tabular}




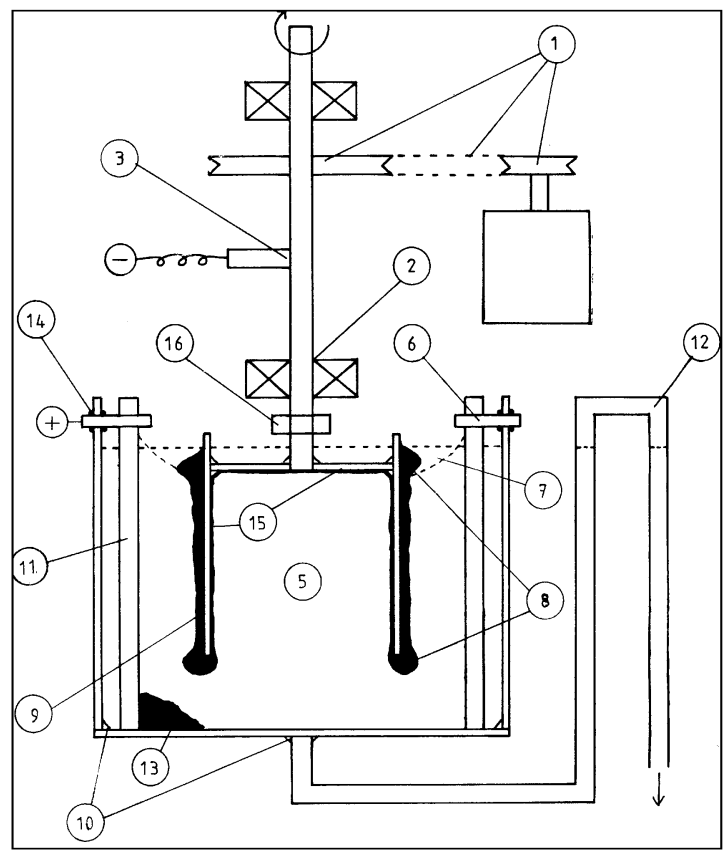

Fig. 5 A summary of fault conditions in rotating cylinder electrode reactors used for photographic silver removal over a period of 20 years: (1) slipping or broken drive belts or pulleys, (2) high friction bearings, (3) high-resistance electrical brush/slip ring connections, (4) vibration at eccentric rotating shaft, (5) non-uniform mixing of the electrolyte, (6) anode connection problems, (7) vortexing in the electrolyte, (8) uneven deposit build-up near the top and bottom of the RCE, (9) eccentric cathodes, (10) poor fabrication of the inlet and tank, (11) wear of the (carbon plate) anodes, (12) syphoning of the reactor contents, (13) redissolution of silver product removed from the cathode, (14) overheating of the anode/tank zone, (15) unwanted deposition on RCE surfaces, (16) eccentric $\mathrm{RCE} /$ shaft coupling.

throughout the experiment, indicating effective exclusion of atmospheric oxygen from the electrolyte. The cadmium removal showed an initially high current efficiency rapidly decreasing to less than 0.2 at about halfway through the experiment, in agreement with the marked deviation in decay rate from the initial value. The final concentration of cadmium was as low as $0.4 \mathrm{ppm}$ [34].

\section{CLEAN ENERGY CONVERSION}

\section{Proton-exchange membranes for fuel cells}

Among the common types of fuel cell [35], proton-exchange membrane (PEM) fuel cells have attracted particular attention in automobile and power supply applications owing to their relatively low temperature of operation and the advanced state of hardware development.

The electrochemical properties of the proton exchange membrane [36] are critical in PEM reactors, and there is a strong trend toward thinner membranes (to obtain a high cell voltage) that have adequate chemical and physical stability, even at the relatively high current densities (typically $>1 \mathrm{~A} \mathrm{~cm}^{-2}$ ) experienced. While earlier PEM cells often employed fluorocarbon-based membranes of thickness $<180 \mu \mathrm{m}$; many modern design are using membranes of ca. $20 \mu \mathrm{m}$ thickness. We have examined the conductivity of a series of 1100 equivalent weight Nafion PEMs (having controlled hydration and 
a

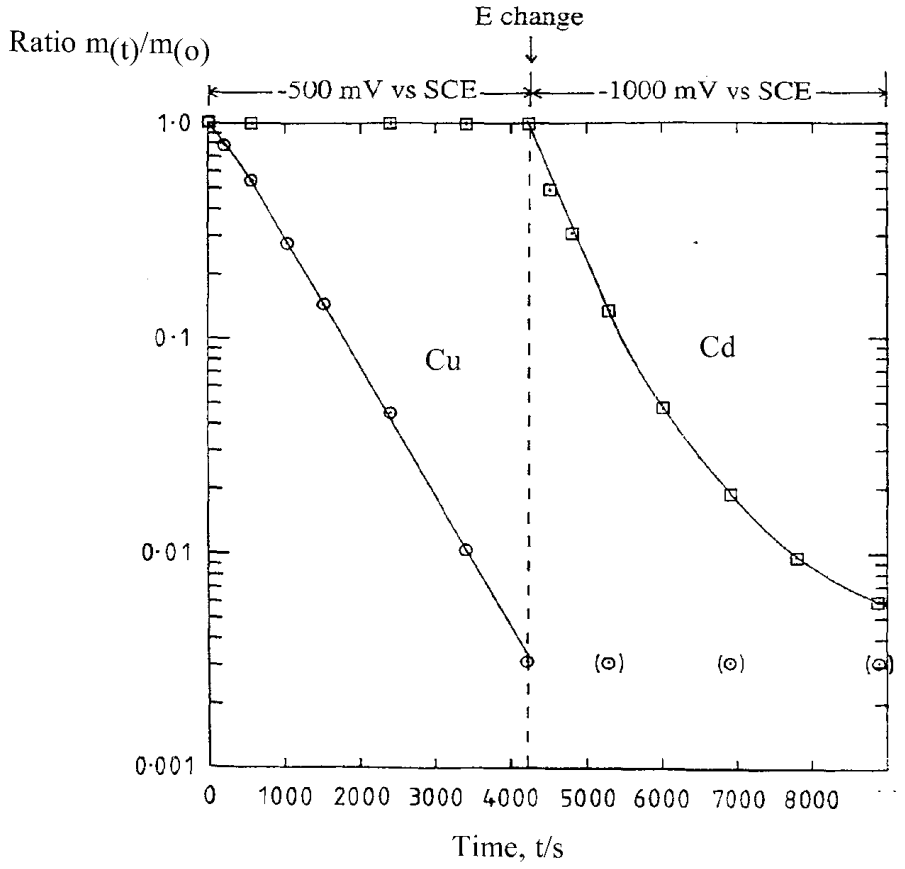

b

Current efficiency, $\phi$

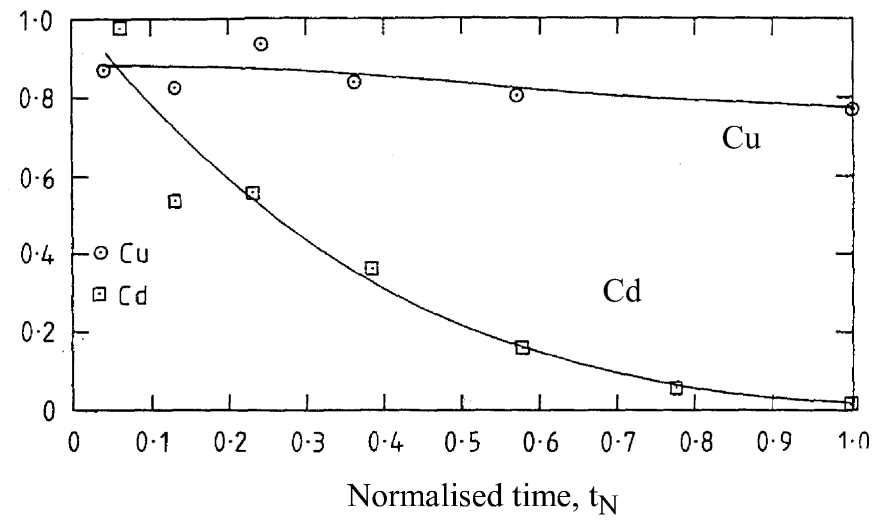

Fig. 6 Removal of cupric ions from an acid sulphate solution $\left(200 \mathrm{~cm}^{3}\right)$ using an RVC RCE (E $=-500 \mathrm{mV}$ vs. SCE) followed by the subsequent removal of cadmium ions ( $E=-1000 \mathrm{mV}$ vs. SCE). (a) Semilogarithmic plot of the ratio of amount of material at time $t$ to that at time zero vs. time. The time at which the potential was changed is indicated in the figure. (b) Current efficiency ( $\phi$ ) vs. normalized time $\left(\mathrm{t}_{\mathrm{N}}\right) \cdot \mathrm{c}_{(0)}=0.50 \mathrm{mmol} \mathrm{dm}{ }^{-3} \mathrm{Cu}(\mathrm{II})$ ions with $0.50 \mathrm{mmol} \mathrm{dm}{ }^{-3} \mathrm{Cd}(\mathrm{II})$ ions in deoxygenated $0.50 \mathrm{~mol} \mathrm{dm}^{-3} \mathrm{Na}_{2} \mathrm{SO}_{4}$ at pH $2 . \omega=157 \mathrm{rad} \mathrm{s}^{-1}\left(1500 \mathrm{rev} \mathrm{min}^{-1}\right)$, $\mathrm{T}=298 \mathrm{~K} . \odot \mathrm{Cd} \odot \mathrm{Cd}$.

hydrated thicknesses of 208, 161, 11, and $58 \mu \mathrm{m})$ under both immersed $\left(1 \mathrm{M} \mathrm{H}_{2} \mathrm{SO}_{4}\right.$ at $\left.298 \mathrm{~K}\right)$ and in situ fuel cell conditions [37]. As an example, Fig. 7a shows the membrane area resistance as a function of hydrated membrane thickness for the range of Nafion membranes. The area resistance clearly increases in a nonlinear fashion as the membrane thickness is increased. The data are plotted in the form of the conductivity and resistivity vs. the hydrated membrane thickness in Fig. 7b. For an ohmic conductor, a horizontal line reflecting the independence of the conductivity or resistivity with sample thick- 
a

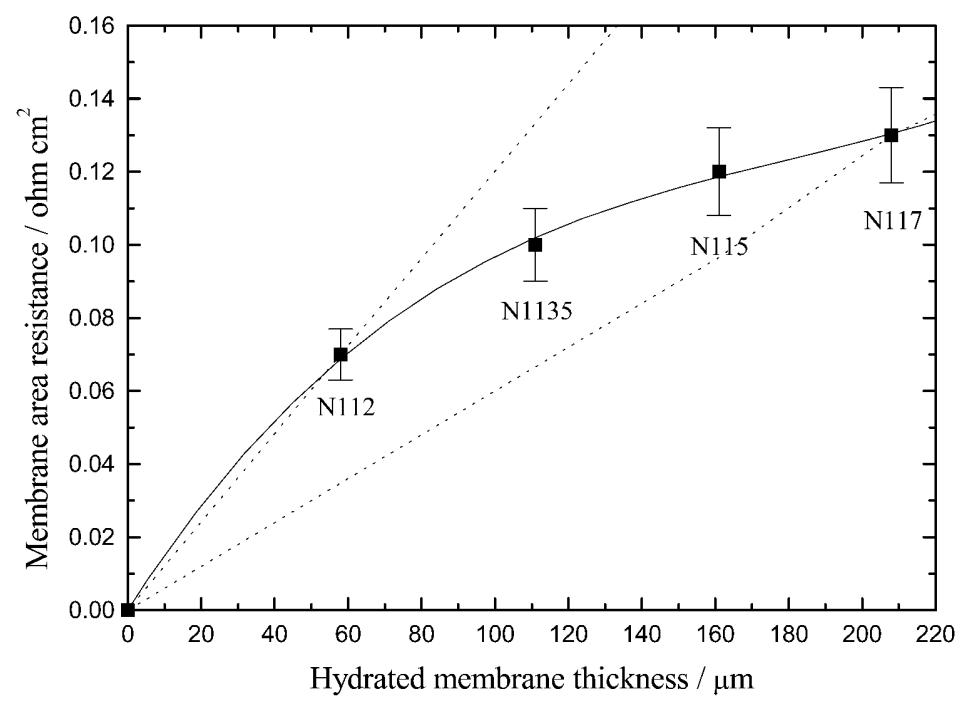

b

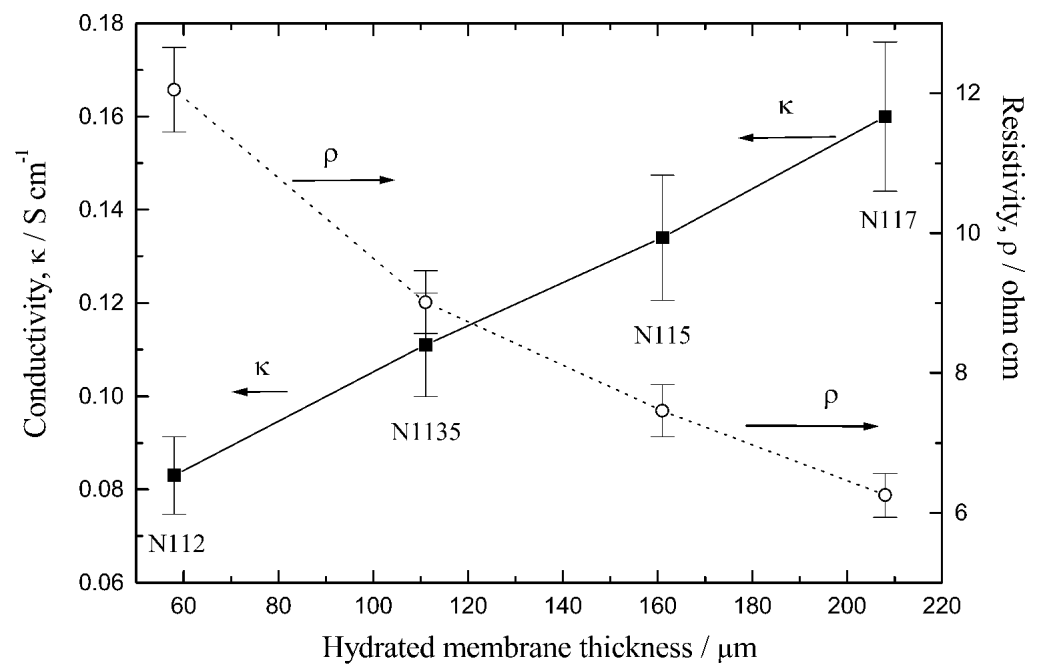

Fig. 7 Variation in the ionic properties of a Nafion $1100 \mathrm{EW}$ series of membranes as a function of hydrated membrane thickness under immersion conditions in $1 \mathrm{M} \mathrm{H}_{2} \mathrm{SO}_{4}$ electrolyte at $298 \mathrm{~K}$. (a) Area resistance vs. hydrated membrane thickness. The upper and lower dotted lines represent the projected ohmic behavior based on N112 and N117, respectively. (b) Conductivity and vs. hydrated membrane thickness.

ness is predicted. The membranes do not show such independence under the experimental conditions. The lower conductivity and higher resistivity of the thinner Nafion membrane materials is clear. Similar behavior has been shown under in situ hydrogen/oxygen fuel cell conditions [37].

PEM reactors are also critically dependent on efficient construction of the membrane electrode assembly (MEA), which usually consists of a precious metal catalyst layer deposited on each side of a proton-exchange polymer membrane. One method of depositing a finely divided platinum layer is by chemical deposition onto the membrane using the reduction of chloroplatinic acid on one side of the membrane by borohydride ion (on the other side). Pt/Nafion 117 structures produced in this fashion are 


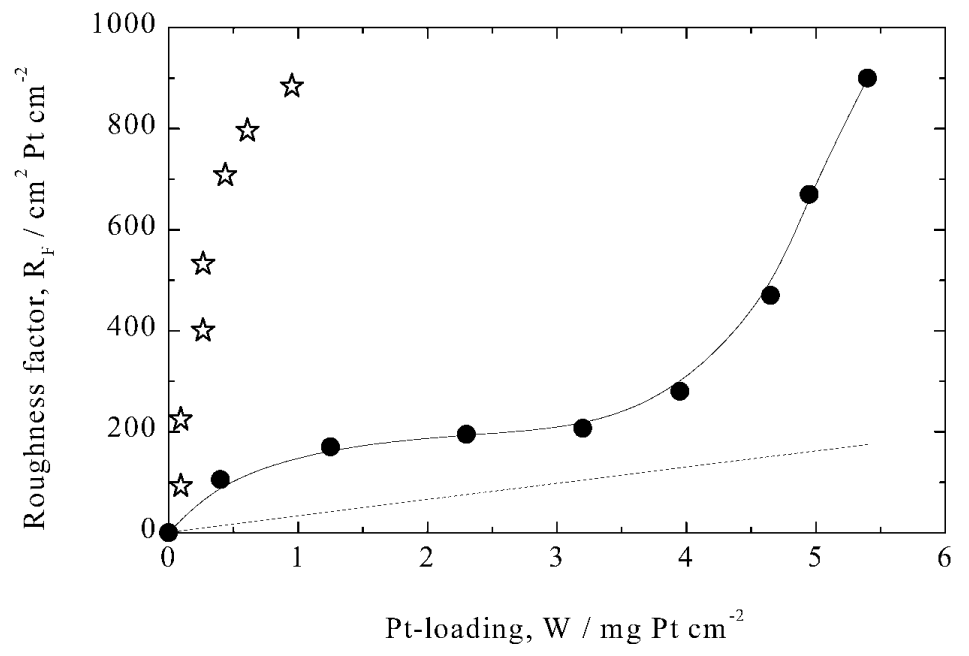

Fig. 8 The relationship between roughness factor (hydrogen adsorption) and platinum loading for a Nafion 117 cation membrane that has been platinized using a borohydride ion reduction of chloroplatinic acid. A roughness factor of one corresponds to a geometrically smooth electrode. The lower, dotted line corresponds to a close packed model of 100-nm spheres. The middle line (filled circles) shows early data [38]. The improved results (asterisks) are obtained by the use of organic electrolyte additives in the chloroplatinic acid.

very dependent on the electrolyte flow conditions and the electrolyte composition [38]. Figure 8 shows the area enhancement of such platinized surfaces (obtained via hydrogen adsorption measurements using cyclic voltammetry in $1 \mathrm{M}$ sulphuric acid) as a function of platinum loading. The use of an electrolyte additive in the chloroplatinic acid is an important process improvement that enables high surface areas to be obtained using relatively low (and hence reasonable cost) platinum loadings on the membrane [38].

\section{Redox flow cells for load leveling}

One of the most marked and largest-scale development in electrochemical technology has been the scale-up of redox flow cells (sometimes called regenerative fuel cells), particularly for load-leveling applications. The most developed systems are based on vanadium-vanadium [39] or bromine-polysulphide [40] (Fig. 9) electrochemistry.

The Regenesys technology [40-42] for load leveling has been developed in the United Kingdom and the United States by National Power, then Innogy Technology Ventures Ltd. (now known as Regenesys Technologies, Ltd.) over the last 8 years. Following extensive R\&D within the company, in several universities, and with commercial partners, filter-press bromine-polysulphide redox flow cells have been operated at three scales (Table 7) using the S-, L-, and XL-series cell stacks (Fig. 10). The technology has been demonstrated up to the XL scale in a 1-MW maximum pilot scale facility at Innogy's Aberthaw power station, near Cardiff, UK, over the last 5 years. A key feature of the modular technology is the ability to volume produce filter-press frames incorporating integral seals and production welding of the (carbon-polyelfin composite) bipolar electrodes into the polymer cell frames. A commercial-size demonstration plant is undergoing construction at Innogy's Little Barford power station in Cambridgeshire, UK. This plant uses up to $120 \mathrm{XL}$ modules, each having 200 bipolar electrodes and is rated at a maximum power output of $15 \mathrm{MW}$, with an energy storage capacity up to $120 \mathrm{MW} \mathrm{h}$ 


\section{+ve electrode cation -ve electrode}

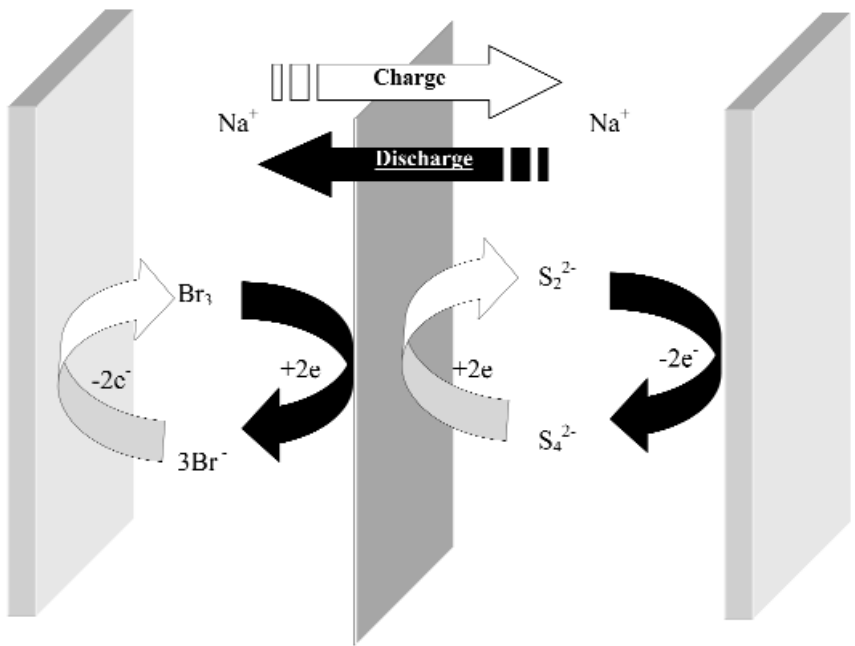

Fig. 9 The principle of a redox flow cell for the storage and delivery of electrical power using tribromide/bromide and polysulphide/sulphide electrolytes separated by a sodium cation-exchange membrane (the Regenesys process).

Table 7 The scales of Regenesys ${ }^{\circledR}$ redox flow cells for load-leveling applications. Bipolar electrodes are assembled into a modular stack using a specialized filter-press type of assembly [40-41].

\begin{tabular}{|c|c|c|c|c|}
\hline $\begin{array}{l}\text { Series of } \\
\text { module }\end{array}$ & $\begin{array}{c}\text { Nominal area of } \\
\text { each bipolar } \\
\text { electrode } / \mathrm{m}^{2}\end{array}$ & $\begin{array}{c}\text { Maximum } \\
\text { number of bipolar } \\
\text { electrodes per stack }\end{array}$ & $\begin{array}{c}\text { Nominal open } \\
\text { circuit stack voltage } \\
\text { /V }\end{array}$ & $\begin{array}{c}\text { Nominal power } \\
\text { rating of stack } \\
/ \mathrm{kW}\end{array}$ \\
\hline$S$ & 0.11 & 60 & 90 & 5 \\
\hline $\mathrm{L}$ & 0.21 & 120 & 180 & 20 \\
\hline XL & 0.67 & 200 & 300 & 100 \\
\hline
\end{tabular}

and two electrolyte storage tanks of $1800 \mathrm{~m}^{3}$ volume [40-42]. Important aspects of the Regenesys reactor technology include:

a) the use of a well-established undivided, filter-press approach to reactor design

b) use of carbon-polyolefin composite electrodes enabling the electrodes to be welded to the polyolefin cell frames using laser-based production engineering techniques

c) bipolar electrodes for simplicity in making electrical connections and to promote a uniform current distribution with a high cell voltage over a stack and a moderate current

d) specially molded polyolefin cell frames having integral electrolyte manifolds and seals

Regenesys load-leveling technology represents one of the largest-ever installations of filter-press cell technology, ion-exchange membrane use, and electrochemical power management. 
a

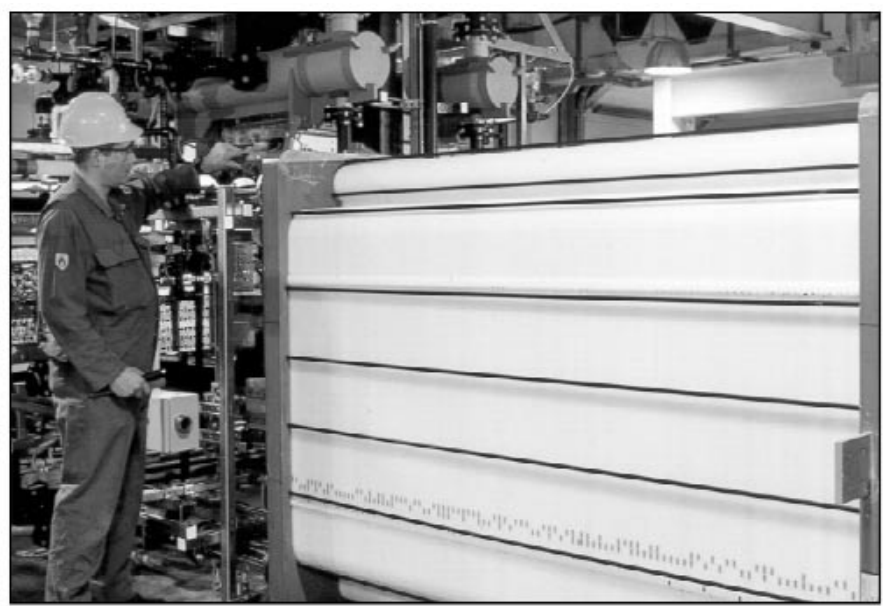

b

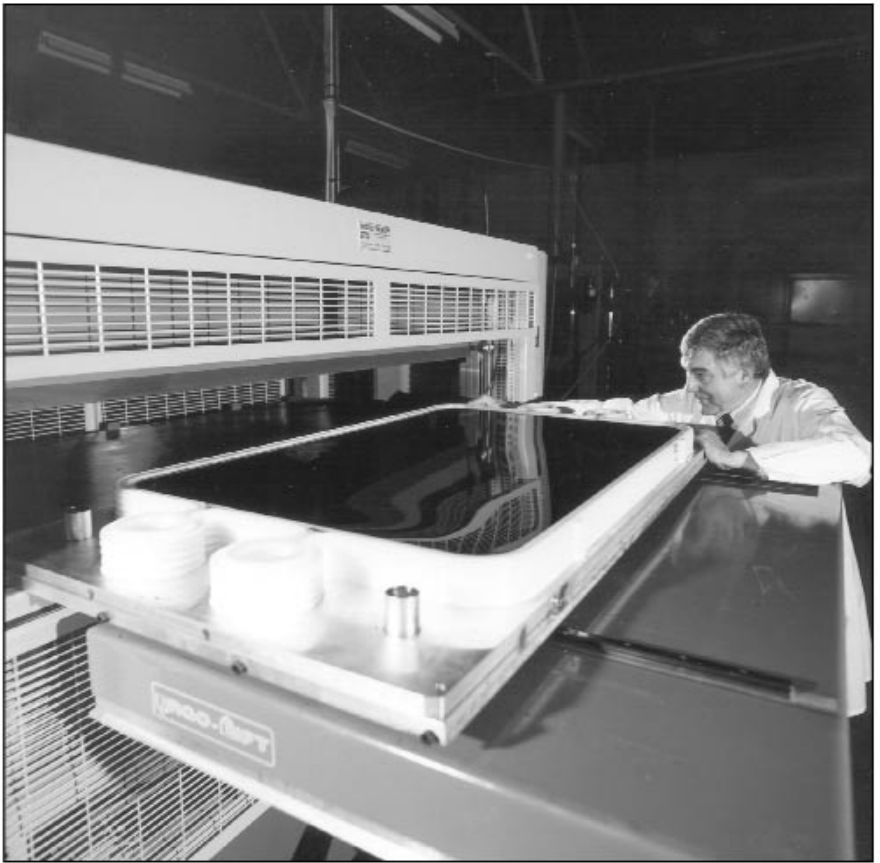

Fig. 10 The Regenesys cells for load leveling in electrical power stations. (a) An XL module containing 200 bipolar electrodes. (b) A single bipolar electrode and cell fame unit undergoing inspection and testing (Regenesys Technologies).

\section{SUMMARY}

\section{Environmental electrochemical technology}

Electrochemical technology is an essential and enabling discipline in many sectors of environmental treatment, including clean synthesis, monitoring of process efficiency and pollutants, removal of contaminants, recycling of process streams, water sterilization, clean energy conversion, and the efficient storage and utilization of electrical energy.

(C) 2001 IUPAC, Pure and Applied Chemistry 73, 1819-1837 
The field of environmental electrochemistry has witnessed many developments and has demonstrated many successes, as evidenced by the growing literature. The present paper has provided the following examples of environmental electrochemistry on the laboratory, pilot and full industrial scale in two application areas:

a) Metal ion removal can be carried out from aqueous, low-concentration solutions using the technologies of electrodialysis and anodic regeneration of reagents and electrodeposition at 3-dimensional cathodes such as RVC, RCEs, and combined RVC RCEs.

b) Clean energy conversion can be achieved using PEMs and membrane electrode assemblies as essential components in PEM fuel cells and related technologies together with the development of large-scale, load-leveling fuel cells based on modular, redox flow cell technology.

\section{Trends in environmental electrochemical technology}

Major trends in reactor design have included [1-17]:

- $\quad$ more compact and modular reactor designs

- $\quad$ production engineering of cell components to allow economic, high-volume production

- development of large-scale bipolar electrode reactors, which offer good current distribution and require only the end-feeder electrodes to be directly connected to a power supply

- $\quad$ increasing availability of porous, 3-dimensional electrodes in carbon or metal

- use of gas-diffusion electrodes not only in fuel cells but also in technologies such as chlor-alkali, pollution control, and organic electrosynthesis

- $\quad$ more efficient solid polymer electrode structures for PEM fuel cells and many other applications

- $\quad$ small gap cells to minimize ohmic losses

- hybrid cells, which combine electrochemical functions with, e.g., gas absorption or ion exchange

\section{Challenges to the development of environmental electrochemistry}

It has been traditional to teach electrochemistry in universities as part of physical chemistry and to stress the more reversible, thermodynamic aspects of the subject. Fortunately, this old fashioned approach is changing, and practitioners in chemistry, materials, and chemical engineering departments are now providing lectures and laboratory classes in modern electrochemistry. The author has advocated an integrated approach to electrochemistry, where the fundamental science and techniques are taught via knowledge of the industrial applications [43]. A case history format is particularly useful in bridging the gap between laboratory science and industrial technology.

The last 10 years have seen the publication of a large number of electrochemistry texts. While most of these consider fundamental electrode kinetics, electroanalysis, and laboratory techniques, there have been some key texts on industrial electrochemistry and electrochemical engineering.

The development of modular courses on aspects of electrochemical engineering is important to the success of industrial processes. It is pleasing to see that a number of short courses are becoming available for postgraduates and industrial delegates. The availability of modular postgraduate courses, suitable for industry or academia is critical to future developments, particularly in the fields of environmental technology, membrane applications, and fuel cell design. Such courses will complement existing provision in, e.g., corrosion, surface finishing, and laboratory techniques in electrochemistry. For example, undergraduate teaching material is available in the areas of fluid dispersion [44], fractional conversion in electrochemical reactors under mass transport control [45], a practical demonstration of simple batteries [46], and the removal of metal ions from solution [47].

The continued development of environmental electrochemical engineering must be seen as critical to the future success of technologies as diverse as solar cells, automotive fuel cells, load-leveling redox batteries, chemicals and biosensors, pollution-control processes, and the synthesis of materials 
and coatings technology for the electronics industry. It is important that postgraduate schools expand teaching, research, and short course training in this important discipline.

In the area of reactor design, continuing challenges to the field of environmental electrochemical engineering include:

- $\quad$ improved electrode structures (having high surface area, improved electrocatalytic ability, and capable of low-cost, volume production);

- $\quad$ improved ion-exchange membranes (having better selectivity, controlled solvent transport, and lower-cost, yet high stability);

- $\quad$ published comparisons between electrochemical routes and chemical/physical ones, for a particular application (e.g., energy transformation, chemical monitoring, synthesis, or pollution control);

- $\quad$ quantitative treatments of the performance of various electrochemical reactors for a particular application (such as metal ion removal or removal of organics);

- accessible case histories of successful electrochemical technologies, which include descriptions of scale-up, process experience, and competitive technologies;

- $\quad$ integration of electrochemical devices and reactors with other devices and unit processes (e.g., optical-electrochemical sensors, electrochemically assisted ion exchange, and combined adsorption/electrochemical treatment of soluble contaminants); and

- $\quad$ an integrated Web site, which provides easy access to the many subfields of electrochemistry (such as corrosion, surface finishing, power sources, electrosynthesis, pollution control, sensors, and electrochemical materials).

An essential need is the development of recognized centers of excellence, where interdisciplinary teams can develop both the science and technology of electrochemistry in close collaboration with industry and government research organizations. Such centers would provide a seamless and two-way transition from a laboratory R\&D environment to pilot-scale electrochemical reactor facilities.

\section{ACKNOWLEDGMENTS}

Contributions by research workers Gavin Reade, Sally Ann Sheppard, Sharon Slade, and Ian Whyte, and my colleagues Dr. Sheelagh Campbell and Prof. Derek Pletcher at the Universities of Portsmouth and Southampton, UK, are grateful acknowledged. This work has been supported by DERA, E A Technology, The ETSU Environmental Technology Best Practice Programme, Johnson Matthey Technology Centre, Innogy Technology Ventures Limited (now Regenesys Technologies), Poeton Industries Limited. and the Engineering and Physical Sciences Research Council. This paper was presented as an introductory lecture to the IUPAC Conference and Workshop on Electrochemistry and Interfacial Chemistry in Environmental Clean-up and Green Chemical Processes, 6-7 April 2001, Coimbra, Portugal.

\section{REFERENCES}

1. D. Pletcher and F. C. Walsh. Industrial Electrochemistry, $2^{\text {nd }}$ ed., Chapman \& Hall, London (1990).

2. F. C. Walsh. A First Course in Electrochemical Engineering, The Electrochemical Consultancy, Romsey (1993); F. C. Walsh, J. Gonzalez-Garcia, V. Montiel Leguey. Un Primer Curso de Ingenieria Electroquimica Imprenta Gamma, San Vicente, Alicante (2000).

3. F. Goodridge and K. Scott. Electrochemical Process Engineering, Plenum Press, New York (1995).

4. G. Kreysa (Ed.). Electrochemical Cell Design and Optimisation Procedures, Dechema Monograph, 123 (1992).

(C) 2001 IUPAC, Pure and Applied Chemistry 73, 1819-1837 
5. D. Pletcher and F. C. Walsh. Chem. Ind. 17 September, 564-566 (2001).

6. C. A. C. Sequeira (Ed.). Environmentally Oriented Electrochemistry, Elevier, Amsterdam (1994).

7. J. O 'M. Bockris (Ed.). The Electrochemistry of Cleaner Environments, Plenum Press, New York (1972).

8. C. Comninellis. In Environmentally Oriented Electrochemistry, C. A. C. Sequeira (Ed.), pp. 77-101, Elsevier, Amsterdam (1994).

9. K. Scott. Electrochemical Processes for Clean Technology, The Royal Society of Chemistry, London (1995).

10. J. D. Genders and N. L. Weinberg. The Electrochemistry of Cleaner Environments, The Electrosynthesis Co., Lancaster, New York (1992).

11. P. M. Bersier. Chem. List 89, 742-755 (1995).

12. A. M. Couper, D. Pletcher, F. C. Walsh. Chem. Rev. 90, 837-865 (1990).

13. T. A. Davis, J. D. Genders, D. Pletcher. Ion Permeable Membranes, The Electrochemical Consultancy, Romsey (1997).

14. F. C. Walsh and G. W. Reade. Analyst 119, 791-803 (1994).

15. F. C. Walsh and G. A. Mills. Chem. Tech. Europe 1 (1), 13-20 (1994).

16. K. Scott and F. C. Walsh. Electrochem. Eng., Chem. Ind. 26 July, $493-497$ (1993).

17. P. M. Bersier, L. Carlsson, J. Bersier. Top. Curr. Chem. 170, 114-229 (1994).

18. F. C. Walsh and G. W. Reade. Analyst 119, 791-803 (1994).

19. D. Pletcher and F. C. Walsh. In Electrochemical Technology for a Cleaner Environment, J. D. Genders and N. L. Weinberg (Eds.), pp. 52-100, The Electrosynthesis Co., Lancaster, New York (1992).

20. F. C. Walsh. Bull. Electrochem. 8, 471-474 (1992).

21. F. C. Walsh, D. Pletcher, I. Whyte. J. Chem. Technol. Biotechnol. 55, 147-155 (1992).

22. F. C. Walsh and G. W. Reade. In Environmentally Oriented Electrochemistry, C. A. C. Sequeira (Ed.), pp. 3-41, Elsevier, Amsterdam (1994).

23. "Reducing Costs in Hard Chrome Plating" ETSU Leaflet FP91, 1999; ETSU, Harwell, Didcot, Oxon OX11 ORA, UK; a collaborative project with Poeton Industries Ltd., PMD (UK) Ltd., Elementis Chromium and FHM Division, Claverham Ltd.

24. I. Whyte, D. Pletcher, F. C. Walsh, J. P. Millington. J. Appl. Electrochem. 21, 667-671 (1991).

25. F. C. Walsh. In The Electrochemistry of Cleaner Environments, J. D. Genders and N. L. Weinberg (Eds.), pp. 101-159, The Electrosynthesis Co., Lancaster, New York (1992).

26. F. C. Walsh. I. Chem. E. Symp. Ser. 98, 139-149 (1986).

27. F. C. Walsh and D. E. Saunders. J. Photog. Sci. 31, 35-42 (1983).

28. M. Fleischmann, C. J. H. King, J. W. Oldfield, R. E. Plimley, C. L. K. Tennakoon. British Patent 1,419,246, (1971).

29. D. R. Gabe, F. C. Walsh, G. D. Wilcox, J. Gonzalez-Garcia. J. Appl. Electrochem. 28, 759-780 (1998).

30. F. C. Walsh and N.A. Gardner. In Electrochemical Cell Design, R. E. White (Ed.), pp. 225-258, Plenum, New York, (1984).

31. D. R. Gabe and F. C. Walsh. I. Chem. E. Symp. Ser. 116, 219-229 (1990).

32. D. Robinson and F. C. Walsh. J. Photog. Sci. 42, 1-11 (1994).

33. A. H. Nahlé, G. W. Reade, F. C. Walsh. J. Appl. Electrochem. 25, 450-455 (1995).

34. G. W. Reade, A. H. Nahle, P. Bond, F. C. Walsh. J. Chem. Technol. Biotechnol. To be submitted.

35. R. Kingston. Chem. Br. 36 (6), 24-28 (2000).

36. O. Savadogo. J. New Mat. Electrochem. Syst. 1, 47 (1998).

37. S. Slade, S. A. Campbell, R. R. Ralph, F. C. Walsh. J. Electrochem. Soc. (2002). Accepted for publication.

38. S. A. Sheppard, S. A. Campbell, J. R. Smith, G. W. Lloyd, T. R. Ralph, F. C. Walsh. Analyst 123, 1923-1929 (1998). 
39. E. Sum and M. Skyllas-Kazacos. J. Power Sources 15, 179-190 (1985).

40. A. Price, S. Bartley, S. Male, G. Cooley. Power Eng. J. 13 (3), 122-129 (1999).

41. Regenesys Technologies Ltd., Harwell International Business Centre, Harwell, Didcot, Oxon, OX110QA, UK; regenesys@innogy.com.

42. F. C. Walsh. The Chemical Engineer, 29-31 October (2001).

43. G. A. Ottewill and F. C. Walsh. Electrochem. Newsletter January, 19-25 (1996).

44. J. A. Conesa, J. Gonzalez-Garcia, J. Iniesta, P. Bonete, M. Ingles, E. Exposito, V. Garcia-Garcia, V. Montiel. Chem. Eng. Educ. Fall, 300-304 (1999).

45. P. Trinidad, F. C. Walsh, D. Gilroy. Int. J. Eng. Educ. 14, 431-441 (1998).

46. X. LeRoux. J. Chem. Educ. 73, 811-817 (1996).

47. G. A. Ottewill, G. W. Reade, S. A. Campbell, F. C. Walsh. Green Chem. (2002). In press. 